\title{
PAVILHÃO DE BARCELONA: UMA OBRA ALÉM DO VIDRO E DO AÇO
}

Leila Barchi, Leandro César, Jaqueline Matos, Jayne Moura, Korina Aparecida Teixeira Ferreira da Costa Costa

Universidade do Oeste Paulista - UNOESTE, Curso de Arquitetura e Urbanismo, Presidente Prudente, SP. E-mail: korina.arq@gmail.com

\section{RESUMO}

O presente artigo, constitui uma pesquisa qualitativa, do tipo revisão bibliográfica e toma como recorte a análise da obra Pavilhão de Barcelona de Mies van der Rohe. Tendo como objetivo expor suas características projetuais mais marcantes e representativas, com o intuito de relacionar os condicionantes de forma, função e estrutura utilizados como referencial de projeto para o edifício, para exaltar seu caráter tectônico, foi desenvolvido um estudo de fundamentação teórica relacionado aos conceitos da poética da estrutura, conforme apresentado pelo arquiteto em estudo na sua obra "Pavilhão de Barcelona", assim como uma contextualização da mesma com o período histórico, referente à primeira metade do século XX e sua representatividade para a promoção de uma nova estética, da geometrização, pureza formal e abstração, conforme preceitos da arquitetura do Movimento Moderno.

Palavras-chave: Pavilhão de Barcelona, Tectônica, Arquitetura moderna, funcionalidade e Mies.

\section{BARCELONA PAVILION : A WORK BEYOND THE GLASS AND STEEL}

\begin{abstract}
This present article constitutes a qualitative study of bibliographical review and takes as clipping the analysis of the work Barcelona Pavilion by Mies van der Rohe. Aiming to expose their most striking and representative projective characteristics, in order to relate the conditions of form, function and structure used as a design reference for the building, to exalt its tectonic character, it was developed a study of theoretical basis related to the concepts the poetic structure, as shown by architect study in his book "Barcelona Pavilion", as well as contextualizing the same with the historical period on the first half of the twentieth century and its representation for the promotion of a new aesthetics, geometrization, formal purity and abstraction, as Modern Movement architecture principles.
\end{abstract}

Keywords: Barcelona Pavilion, Tectonics, Modern architecture, functionality and Mies. 


\section{INTRODUÇÃO}

O século XX foi palco de grandes transformações devido ao progresso técnico expresso pelas Revoluções Industriais na Europa que fomentaram grandes transformações na sociedade como um todo. Com a arquitetura não foi diferente, o Movimento Moderno foi responsável por significativas mudanças presentes até hoje. Dentre outros arquitetos que contribuíram para esse movimento estava Ludwig Mies van der Rohe.

O Movimento Moderno se estendeu entre 1915 a 1945, tendo por princípios básicos as correntes vanguardistas ligadas à sociedade industrial, que seria baseada na funcionalidade, pureza geométrica e industrialização dos materiais e métodos.

Uma figura de grande importância para o Movimento foi a escola alemã Bauhaus, primeira escola de design e arquitetura que discutia os ideais do Modernismo, esta que teve um papel decisivo por ser um dos principais articuladores do discurso de industrialização ligado a arquitetura, influenciando diversos arquitetos. (CASTELNOU, 2015)

Mies nasceu em 1886 em Aachen, Alemanha. Desde cedo esteve envolvido com a arquitetura, trabalhando com seu pai (mestre de obras), arquitetos locais e posteriormente com o designer Bruno Paul em Berlim, além de Peter Behrens, o arquiteto de maior progresso na época e um dos principais membros da Deutscher Werkbund. (ECKARDT, 2013)

As obras de Mies após 1923 refletem influencias, como, construção em alvenaria (Berlage), horizontalidade (De Stijl e F. L. Wright) e planta livre (Suprematismo de Malevich). (FRAMPTON, 1997). Após 1927, Mies van der Rohe já é um dos principais arquitetos da Europa, projetando diversas obras, entre elas, a Casa Tugendhat que despertou o interesse da elite, e o Pavilhão de Barcelona, sua obra mais famosa do período entre guerras.

Tempos depois de a Bauhaus (dirigida por Mies) ser fechada, ele mudou-se para os Estados Unidos onde executou várias das suas mais importantes e conhecidas obras como o Crown Hall, o Edifício Seagram e a Casa Farnsworth, cada uma de monstra um pouco das características de Mies, a ideia de "menos é mais" e o uso de aço e vidro. Mies faleceu em 1969, porém sua significância está presente em obras arquitetônicas até hoje. (ECKARDT, 2013)

\section{METODOLOGIA}

A metodologia basea-se numa investigação bibliográfica e se fundamentará numa abordagem qualitativa de pesquisa, utilizando-se como instrumento um levantamento bibliográfico e documental, que segundo Teixeira (2000, p. 137), busca a correlação entre a teoria e os dados, entre o contexto e a ação, a partir da compreensão dos fenômenos por meio de sua 
descrição e interpretação. Para o trabalho com o estudo do tipo de levantamento bibliográfico ocorrerá inicialmente um levantamento das principais produções no contexto nacional de estudos, considerando a peculiaridade do objeto de estudo.

Desse modo, percebe-se que a pesquisa qualitativa vale-se do método indutivo, segundo o qual parte da observação, da análise dos fatos particulares, dos registros para compor um quadro compreensivo para então constituir a generalização universal, ou seja, a teoria. O processo de indução vale-se do princípio do empirismo, no qual o conhecer é dar significado à realidade (KÖCHE, 1997, p. 62).

\section{A OBRA DE MIES VAN DER ROHE}

Mies Van Der Rohe seguiu uma concepção de linhas puras na arquitetura. Isto significa que seus desenhos eram desenvolvidos na maior parte em linhas retas, que se unem sempre na perpendicular, nos fazendo percorrer os detalhes com os olhos e dando a impressão de movimento ao projeto. Apesar do uso de concreto bruto, Van Der Rohe consegue, graças a suas linhas, um visual bastante agradável e sofisticado (MAYER, 2012).

Mies definiu seu próprio estilo como "pele e osso" devido ao emprego de uma técnica perfeita com uma abordagem racional e limpeza formal. Produziu uma arquitetura da simplicidade formal, ideia que culminou o minimalismo. Seguindo as obras de Mies e capacidade técnica demonstrada ao longo dos anos, podemos ressaltar algumas de suas ideias:

A arquitetura é a vontade de uma época traduzida em espaço, devendo ser guiada pela grande fluidez e ressonância geométrica e material (edifícios não encerrados em si mesmos, mas caracterizados por volumes e superfícies que fluem entre si).

A forma não deve ser o objetivo da arquitetura, pois em si ela não existe; ela deve ser um meio de integração, pois como objetivo em si é puro formalismo; Os problemas da construção restringem-se à estrutura, às disciplinas de projeto e à industrialização dos métodos, ênfase do empenho tecnológico dos elementos funcionais e do conhecimento científico dos materiais de construção (CASTELNOU.2015, p. 43)

Por consequência das influências da industrialização, o uso do vidro e do aço se tornou um dos elementos principais utilizados nos trabalhos de Mies e de outros modernistas. De uma forma geral, Mies também trabalha com a relação dos espaços internos com o meio exterior. Podendonos dizer que ele buscava uma conexão visual, em busca da integração dos espaços e permeabilidade visual (BLASER, 1977). 
Mies busca uma abstração inspirada na arquitetura do classicismo, com o legado do racionalismo em seus procedimentos de construção. Existem três princípios formais que acompanham arquitetos desse período como Le Corbusier e Mies van der Rohe, são eles: a volumetria e a dinâmica; regularidade ao invés de simetria axial acadêmica; presença da perfeição técnica sem decoração exagerada. (MONTANER, 1997).

Se fosse necessário escolher um trabalho como o mais perfeito, essa escolha recairia provavelmente sobre o Pavilhão Alemão de Barcelona, de 1929. Mies provou o que os inimigos do novo estilo sempre negaram - que era possível atingir a monumentalidade, não por meio de falsas colunas, mas sim por meio de materiais esplêndidos e um ritmo espacial imponente. (Pevsner, 1982, p. 433).

Sabe-se que as obras de Mies são de extrema relevância, assim, para representar um aprofundamento para o estudo, a presente pesquisa, focará na obra "Pavilhão de Barcelona".

\subsection{FUNÇÃO}

Autores como Benevolo (2009) e Blaser (1977) julgam o Pavilhão de Barcelona como um marco histórico do movimento moderno. Na Exposição Universal de Barcelona, em 1929, o pavilhão foi construído para representar a Alemanha, a fim de promover o Progresso Industrial e Tecnológico, decorrente da $1^{\circ}$ Guerra Mundial, explorando as novas práticas tecnológicas e científicas.

Segundo Andreotti (2015) e Tonetti (2013) a exposição tinha o objetivo de revalorizar a cidade em todos os seus aspectos sejam eles sociais, econômicos, políticos ou culturais. Cada país tinha o seu próprio Pavilhão e usufruíam dele resumidos dentro de sua filosofia e estilos próprios. Mies van der Rohe é contratado para projetar o Pavilhão de Barcelona com o propósito de demonstrar o caráter progressista, democrático, próspero e pacifista da Nova República Alemã. Ao ser questionado sobre o que seria exposto no pavilhão, Mies teria respondido que nada seria exposto, o pavilhão por si só era a exposição.

Mies consegue, ao longo do processo, alterar o local original de implantação para uma área fora dos muros do palácio de Exposição. Concordou em trabalhar sua obra em um local mais tranquilo onde o pavilhão iria oferecer pontos de vista e escolhe uma posição que lhe confere uma articulação privilegiada, relacionando edifício e entorno (TONETTI, 2013)

Foi projetado de forma a convidar as pessoas que por ali passam e induz os caminhos dos visitantes com a disposição de painéis de mármore travertino. A entrada leva a um pátio central, parcialmente ocupado por um espelho d'água. A implantação desse espelho d'água faz com que 
seja preciso dar uma volta de $180^{\circ}$ para penetrar no edifício. Depois do giro, passa-se uma ideia de leveza de sua forma, devido à composição do vidro combinado com a fina cobertura em concreto armado tendo a impressão de o teto flutuar sobre os pilares. (ANDREOTTI, 2015)

O edifício é construído sobre um alto pódio e se baseia em um elegante conjunto de planos ortogonais independentes entre eles e permite um constante fluido com o ambiente exterior pelas amplas e generosas vidraças. Essa ideia de transparência e fluidez éa base do significado da obra. (ANDREOTTI, 2015, s/p)

O conteúdo do Pavilhão pode ser dividido em duas: os mobiliários, muito deles desenhado pelo próprio Mies; e obras de arte, com destaque para a escultura "Amanhecer" de Georg Kolbe colocado em um dos espelhos d'água. (PELLEGRINI, 2011)

Os espaços definidos pela cobertura definem dois blocos, um retangular que abrigava a exposição, e outro menor quadrado destinado aos serviços. Apesar da simples setorização, planos verticais e horizontais sugerem o espaço tridimensional (SALES, 2009). O teto, piso e paredes, em vez de compor um fecho contínuo, criam espaços retangulares independentes que são acentuados pelos diferentes materiais enquanto a continuidade espacial é enfatizada pela continuidade do material no piso. (BONTA, 1975)

Com o fim da feira internacional, o pavilhão foi desmontado por se tratar de uma construção efêmera feita para a exposição. Porém, por sua importância na arquitetura moderna, foi reconstruída no mesmo local entre 1983 e 1986, por arquitetos espanhóis, que baseando nos recursos disponíveis e muito detalhados deixado por Mies, reconstruíram o Pavilhão sendo fiel ao original.

\subsection{ESTRUTURA}

O Pavilhão segue o conceito modernista da planta livre, que permite a fachada com materiais de menos resistência, como o vidro, trabalhando a harmonia e transparência. Os pilares de concreto armado ou aço são os protagonistas estruturais do modernismo. Mies utiliza pilares de aço cromado em perfil cruciforme. Como diz Montaner (1997), uma arquitetura como sanduíche, com perfeição platônica, provida de duas partes principais, planas e simétricas: chão e teto. A cobertura do Pavilhão está exposta e com os apoios principais em oito pilares distribuídos ao longo do edifício, sendo possível observar essa leveza visual, trazendo uma sensação de fluidez.

Os edifícios de Mies apresentam um caráter tectônico que, conforme Cecília (1996) decorre da utilização da própria estrutura como geradora do espaço arquitetônico e definidora de sua aparência. Assim procedeu Mies van der Rohe no projeto do Pavilhão de Barcelona onde a 
interdependência mutua e harmônica entre forma, função e estrutura concorre para a ativação do pleno potencial tectônico do edifício, condicionando sua manifestação visual e aparência. (SALES, 2009)

É possível observar a tectônica no Pavilhão também pelo pé-direito de 3,10m que foi definido a partir da altura de duas placas de ônix (1,55m cada). O vidro usado como elemento de vedação faz com que haja uma integração dentro/fora, além de provocar um jogo de reflexos. (SALES, 2009)

Mies expressa a ideia de que "menos é mais" que surgiu com o objetivo de obedecer a exigências culturais, ecológicas e econômicas da época. Uma construção que expressa a busca pela funcionalidade. São utilizados materiais tecnológicos e naturais, que podem ser desmontados, dando destaque para o detalhe e significância para cada um deles. Entre esses materiais, estão placas de mármore e ônix dourado, e três tipos de vidros. Com a forma seguindo a função, os elementos estruturais se tornam estético-construtivos, direcionando para atender a função do local sem a necessidade de decoração. (ANDREOTTI, 2015)

\subsection{FORMA}

A composição do Pavilhão baseia-se em linhas retas e formas geométricas puras como o quadrado e o retângulo, porém, não há a ideia de um volume fechado devido a sua cristalinidade, planos em balanço e a leveza expressa pelo edifício. Isso demonstra a distinção entre piso, paredes e cobertura que Mies considera como os elementos tectônicos essenciais (WEST, 1994).

Forma, função e estrutura se harmonizam para formar o edifício, a estrutura do Pavilhão de Barcelona gera a sua forma detalhada e simultaneamente dá lugar a sua função. Esses três elementos se interligam, à medida que um é explorado o outro surge automaticamente.

Em um dos espelhos d'água do Pavilhão, emerge a estátua de George Kolbe, posicionada em um canto escolhido por Mies onde os efeitos ópticos da água teria um impacto mais forte para o visitante. A estátua se protege com a mão do sol que incide em seu rosto. De vários locais internos do edifício há possibilidade de visualizar a escultura. (ANDREOTTI, 2015)

\section{CONSIDERAÇÕES FINAIS}

Sendo construído para representar o êxito da Alemanha, o Pavilhão surgiu em um período amotinado da Europa. Mesmo com sua simplicidade formal e volumétrica, Mies alcança a monumentalidade com a mescla de materiais naturais com os industrializados, trazendo consigo as inovações técnicas e os conceitos modernistas, assim, a obra era por si o objeto exposto. 
Sua significância se deu pela concretização de seu objetivo, que era expor o avanço técnico-estético através do Pavilhão conseguindo uma fluidez e uma leveza exaltada pela estrutura, representando assim o pensamento moderno, pela sua singularidade das formas, leveza e a possibilidade de fazer uma arquitetura limpa e simples, sem diminuir seu valor quanto objeto arquitetônico.

\section{REFERÊNCIAS}

ANDREOTTI, Enzo. El pabellónalemán de la exposición universal de barcelona de 1929. Disponível em: < https://www.youtube.com/watch?v=R49MIzt1lfQ>. Acesso em: 18 de março de 2015.

BENEVOLO, Leonardo. História da arquitetura moderna. São Paulo: Perspectiva, 2009.

BONTA, Juan Pablo. Anatomía de la interpretacíon em arquitectura: Reseña semiótica de la crítica del Pabellón de Mies van der Rohe. Barcelona: Editorial Gustavo Gili, S.A, 1975.

BLASER, Werner. Mies van der Rohe. São Paulo: Martins Fontes, 1977.

CASTELNOU, Antonio. Arquitetura contemporânea. Curitiba: Universidade Federal do Paraná UFPR, 2015. 156p.

CECÍLIA, Bruno Santa. Tectônica moderna e construção nacional. 2006. MDC, Revista de arquitetura e urbanismo. Disponível em: <http://mdc.arq.br/2006/01/31/tectonica-moderna-econstrucao-nacional>. Acessoem: 20 mar 2015.

ECKARDT, Wolf Von. American architect: Ludwig Mies van der Rohe. 2013. Britannica Encyclopedia. Disponível em:<http://www.britannica.com/EBchecked/topic/381736/LudwigMiesvan-der-Rohe>. Acesso em: 18 março 2015.

FRAMPTON, Kenneth. História e crítica da arquitetura moderna. São Paulo: Martins Fontes, 1997. $\mathrm{KÖCHE}$, J. C. Fundamentos de metodologia científica: teoria da ciência e iniciação à pesquisa. 22. ed. São Paulo: Vozes, 2004.

MAYER, Teresa. Mies van der Rohe. 2012. Disponível em: <https://www.westwing.com.br/magazin/historias/mies-van-der-rohe>. Acesso em 20 mar 2015.

MONTANER, Josep Maria. A modernidade superada. Arquitetura, arte e pensamento do século XX. Barcelona, Gustavo Gili S.A., 2001.

PELLEGRINI, Ana Carolina Santos. Quando o projeto é patrimônio: a modernidade póstuma em questão. 2011. Tese (Doutorado). PROPAR/URFRS, Porto Alegre, 2011.

PEVSNER, Nikolaus. Panorama da arquitetura ocidental. São Paulo: Martins Fontes, 2002. 2 ed.

SALES, Emanuel. Estrutura e espacialidade na obra de Mies van der Rohe. 2009. Dissertação (Mestrado). UFRGR/PROPAR, Rio Grande do Sul, 2009.

TEIXEIRA, E. As três metodologias. 2a .ed. São Paulo: Vozes, 2000. 
TONETTI, Ana Carolina. Interseções entre arte e arquitetura: o caso dos pavilhões. 2013. Dissertação (Mestrado). FAU/USP, São Paulo, 2013.

WEST, Christopher. A critical analysis of the tectonic concepts in the trought and work of Ludwig Mies van der Rohe. 1994. Dissertação (Mestrado). Rice University, Houston, 1994. 